\title{
Assessment and Simulation of Evacuation in Large Railway Stations
}

\author{
Yue $\mathrm{Wu}^{\mathrm{a}}$, Jian Kang ${ }^{\mathrm{b}}$, Jingyi $\mathrm{Mu}^{\mathrm{a}^{*}}$ \\ ${ }^{a}$ Key Laboratory of Cold Region Urban and Rural Human Settlement Environment Science \\ and Technology, School of Architecture, Harbin Institute of Technology, No.66 West Dazhi \\ Street, Harbin 150001, China \\ ${ }^{\mathrm{b}}$ UCL Institute for Environmental Design and Engineering, The Bartlett, University College \\ London, London, UK \\ *Corresponding Author \\ Dr. Jingyi Mu,mujingyi@hit.edu.cn
}

\begin{abstract}
Evacuation systems in buildings are frequently assessed to improve emergency response processes. This paper proposes a method to evaluate the performance of different evacuation modes, and determine a rational mode for large railway stations. We developed a simulation for the evaluation of fire safety in large buildings based on an analytic hierarchy process (AHP) method. This approach includes AHP-based exploration and simulation-based refinement. We considered a typical railway station for validation, conducted a field survey to collect the data, and calculated the influencing factors based on expert opinion. The influencing factors were further processed based on the principles of a hierarchical model. The relative weights of the influencing factors were calculated through a series of pairwise comparisons using the AHP. Further, we applied factor refinement based on the evacuation simulations to determine the degree and status of influence of each factor. The influence of external factors was generally stronger than that of the internal factors. Among them, the building component characteristics and people's physiological capabilities were the core of the evacuation assessment in large railway stations. Additionally, the exit width, seat layout, visibility, speed, and reaction capabilities were crucial to the evacuation process. The proposed method is practical as it demands limited computations to provide useful information, such as a priority ranking of each influencing factor, for the evaluation process.
\end{abstract}

Keywords: analytic hierarchy process; risk analysis; large railway station; evacuation simulation

2021 Building Simulation

Date received: 02 July 2020, Date accepted: 01 December 2020

Publish online: 30 January 2021 


\section{Introduction}

A large railway station is defined by a maximum assemblage of more than 10,000 passengers (Zheng et al. 2008). Every day, 20-30 million people take trains from large railway stations in China. A waiting hall presents the largest fire hazard because of its large volume (Zhou, 1990). A method of evacuation assessment for waiting halls in large railway stations can help to guide the establishment and improvement of emergency response scenarios.

Researchers have proposed both subjective and objective methods of evaluating the risk involved in the evacuation process. Subjective evaluation methods include questionnaires and interviews. The study of the psychological and physiological status of humans during an evacuation was pioneered by Bryan (1957), who conducted a questionnaire- based survey on the behavior of people in Arundel Park Hall in Brooklyn. Wood (1972) gathered response data on fire scenarios via interviews and questionnaires, with more than 2,000 staff members from nearly 1,000 fire cases in the UK participating in that survey. Shields et al. (2009) investigated the behavior and experiences of six evacuees of the World Trade Centre (WTC) using pre-interview questionnaires, along with the free-flow and semi-structured interviews. The study discussed the faced by disabled people in terms of fire evacuation planning and design, route widths, group behavior, and emergency preparedness. McConnell et al. (2010) designed a data elicitation tool comprising a pre-interview questionnaire, a one-to-one interview protocol with free-flow narratives, and semi-structured interviews to investigate the cue recognition and response patterns of WTC evacuees. In addition, several studies analyzed the behavioral characteristics of different categories of people in emergencies. Ashe and Shields (1999) studied the behavioral characteristics and reactions of elderly people, children and people with disabilities in fires. Li and Lee (2008) investigated the variations in the evacuation of 180 individuals and found that the training experience, gender, and age were the distinctive features influencing the evacuation behavior.

Objective evaluation methods focus on simulating the evacuation process. They analyze the data that cannot be obtained through subjective surveys, such as response times (Sime 2001), fire spread (Abolghasemzadeh 2013), and exit congestion (Ozel 2001; Carey and McCartney 2004). Researchers have proposed models based on the patterns of animal migration or water movement to simulate the evacuation of individuals, and approximately seventy types of evacuation models are established (Lovreglio et al. 2020). These models were developed based on the data collected from controlled experiments (Guo et al. 2012), group experiments using animals (Saloma et al. 2003; Shiwakoti et al. 2011) and evacuations in a virtual environment (Meng and Zhang 2014). Based on the above models, several software tools were developed to predict the evacuation process, such as EXODUS (Galea and Galparsoro 1994), SIMULEX (Thompson and Marchant 1995a, b), EGRESS (Ketchell et al. 1995), SGEM (Lo et al. 2004), EVACNET (Kisko and Francis 1985), Pathfinder (Thunderhead Engineering 2012), STEPS (Mott MacDonald Simulation Group 2012), EgresSIM (Nam et al. 2016), and EcoSmart Fire (Dietenberger and Boardman 2017). In our study, we used SIMULEX for the evacuation simulation, as it is powerful, flexible, and extremely direct. It was designed to simulate the movements of thousands of individuals escaping a large, geometrically complex building based on multiagent systems (Thompson and Marchant 1995a). It simulated evacuations from structures such as commercial stores (Thompson and Marchant 1995b), crowded airport terminals (Chow and $\mathrm{Ng}$ 2008), multistory buildings (Thompson et al. 1996), campus buildings (Olsson and Regan 2001), railway tunnels (Kennedy et al. 2001) and transit stations (Chen and Chin 2000). It is appropriate for buildings with numerous people concentrated in large spaces (Chang et al. 2016; Xu et al. 2019).

However, the existing tools of evacuation simulation cannot accurately assess the risks presented. For example, for waiting halls in large railway stations, which typically feature high crowd densities in large spaces, many factors influence the evacuation process, and these factors cannot be simply described as increasing or decreasing but rather have fuzzy characteristics. Moreover, some uncertain factors are non-quantifiable, making them unamenable to statistical methods, such as emergency broadcasts (Carlson et al. 2014), evacuation common sense (Pires 2005), emergency reaction ability (Zhao et al. 2009), etc. Therefore, we need to determine the factors affecting the evacuation process using subjective evaluation methods, establish a hierarchy of influencing factors 
using the multi-hierarchy fuzzy method, and determine the degree and status of influence of each factor based on the simulation analysis. In the study reported in the present paper, a typical waiting hall in a large railway station in China was chosen based on site survey data, and the internal and external influencing factors affecting the evacuation process were determined through interviews. Then, a hierarchical model of influencing factors was established, and the weights of these factors were determined using the Analytic Hierarchy Process (AHP). Finally, factor refinement based on evacuation simulation software was applied to determine the degree and status of influence of each factor in different simulation scenarios.

\section{Methodology}

In this paper, a combined method is proposed to assessment and simulate the integrated crowd evacuation in large railway stations, as shown below.

1) Selection of influencing factors.

A pool of influencing factors was explored based on the previous related works, and the factors were selected using the Delphi method (Dalkey 1969). The survey process include one-to-one interview protocol with free-flow narratives and semi-structured interviews.

2) Determining the factor weights.

The influencing factors were divided into five levels of subfactors corresponding to varying degrees of specifications: the target level, the element level, the sub-element level, the operation level, and the suboperation level. The set of weights of the subfactors was calculated using the AHP. The YAAHP 11.3 software (Shanxi Yuan Decision Software Technology, Co., Ltd, http://www.metadecsn.com/yaahp/) was adopted to build a hierarchically structured model and determined the factor weights.

3) Influencing factor refinement.

Based on the constructed AHP model, we collected the relevant data on the influencing factors, and the computer simulation software SIMULEX was used to test the degree and status of influence of each factor on the evacuation process.

\subsection{Survey sites}

A large railway station in China can maximally accommodate between 10,000 and 20,000 people. The research object, a large, oversized rectangular space of the railway station, is an open waiting space with a typical volume of more than one million cubic meters, dominated by a lounge area and flanked by shops, ticket gates, restaurants, and toilets, as shown in Figure 1.

Thus, a typical large railway station in China was the subject of our study. The volume of the waiting hall of this station was $15,600 \mathrm{~m} 3$, with the length and width being 230 and $68 \mathrm{~m}$, respectively. According to the station design, a maximum of 11,000 people can be accommodated in the waiting area. The floor plan with the waiting area marked in gray is shown in Figure 2.

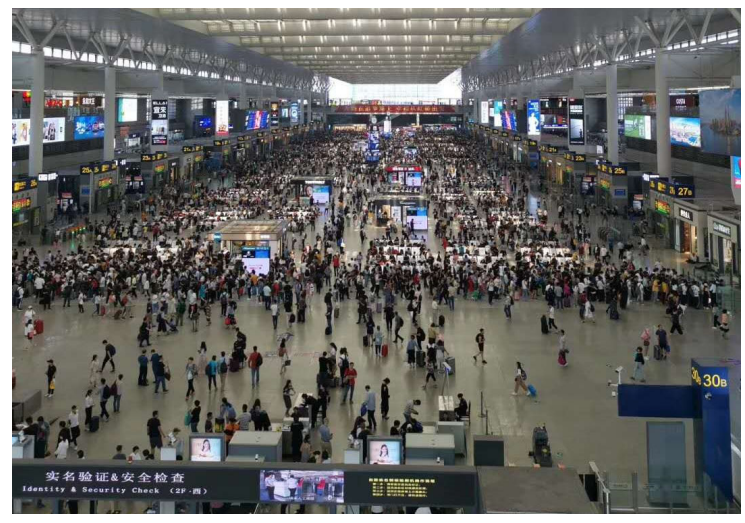

a) Shanghai Hongqiao Railway Station

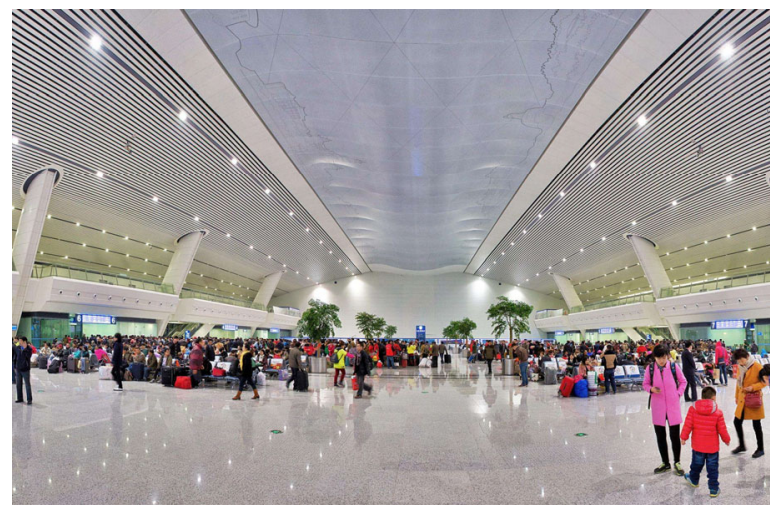

b) Xiamen Railway Station 


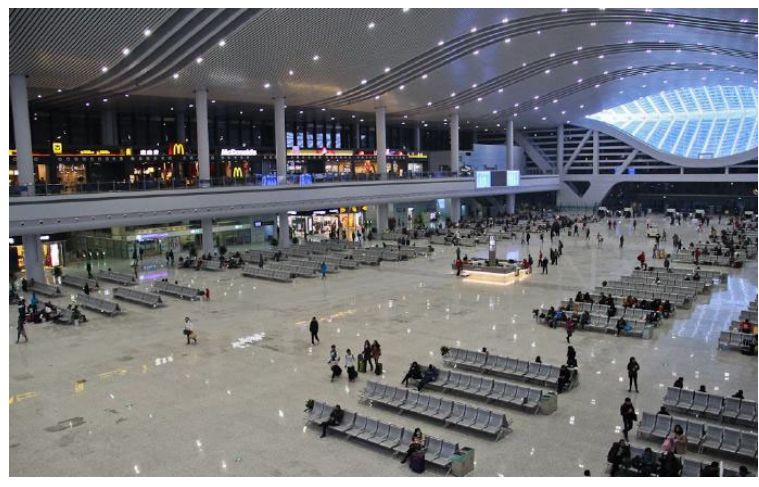

c) Ningbo Railway Station

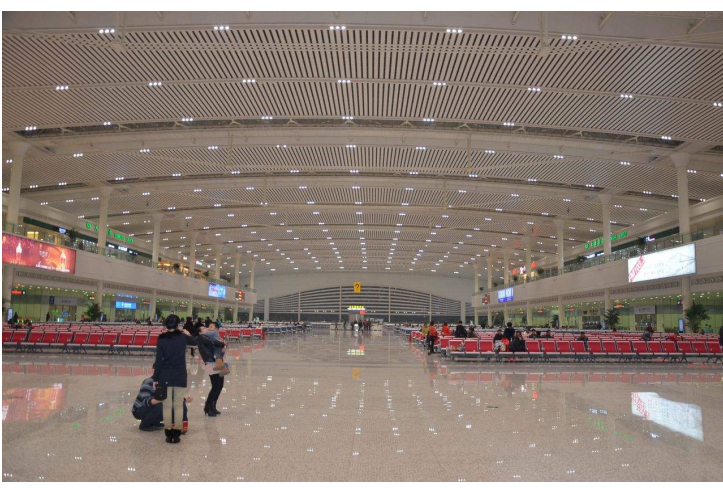

d) Dalian North Railway Station

Figure 1. Some typical waiting halls in large railway stations in China

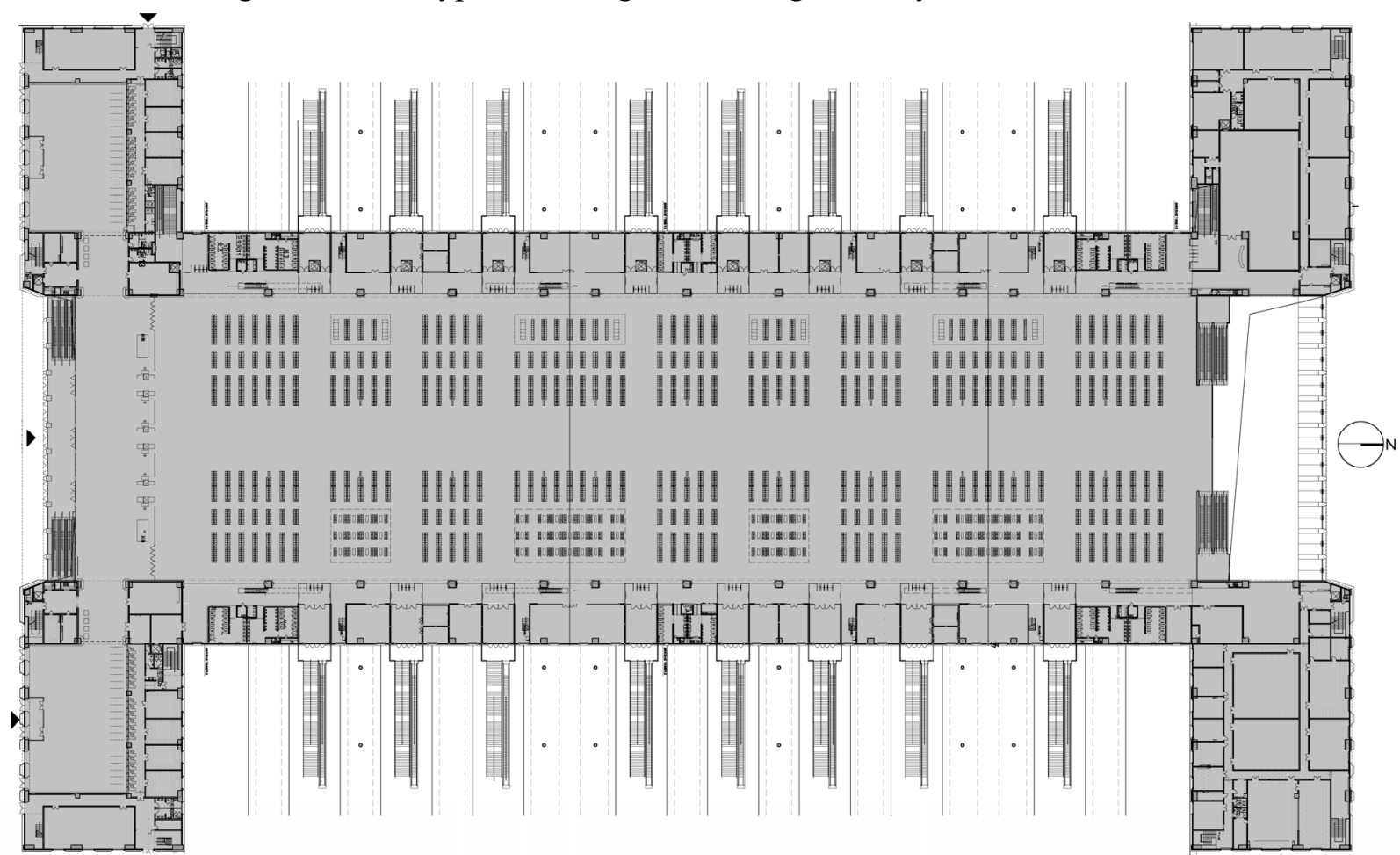

Figure 2. Floor plan of the representative railway station waiting hall

\subsection{Analytic Hierarchy Process}

The AHP, developed by Thomas Saaty in 1971 (Wind and Saaty, 1985), is a core ergonomics approach with a pedigree of more than 30 years. It is a hierarchical weight decision analysis method based on the network system theory and multi-objective comprehensive evaluation method (Phipps et al. 2011).

\section{Influencing factor selection}

The factors that could influence the evacuation were identified and classified as either internal (Bryan 2002; Rød et al. 2012; Vilar et al. 2014; Yue et al. 2014; Shiwakoti et al. 2015; Fridolf et al. 2016) or external (Steinfeld 2006; Gray- Graves et al. 2011; Ronchi et al. 2012; Bode and Codling 2013; Kuligowski 2013; Wang et al. 2013) based on the literature review. Figure 3 depicts the initial AHP model built using the YAAHP software.

Four types of participants were involved in the survey, including four station designers, two station managers, four station staff members and ten passengers. The participants were briefed on the purpose of the session and interviewed individually, after they provided written informed consent to participate in the research. We conducted interviews regarding the influencing factors that affect the evacuation process. Based on the survey results, the AHP model was extended, as shown in Figures 4 and 5. 


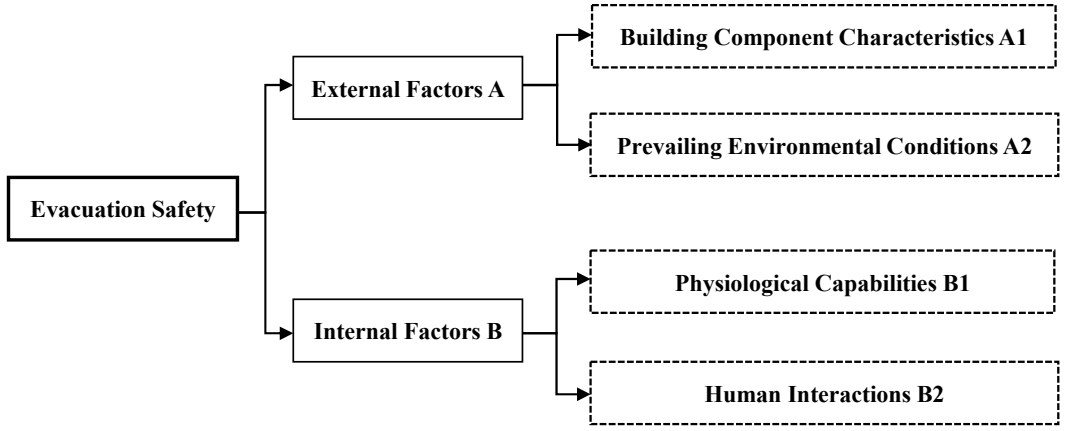

Figure 3. Initial AHP model

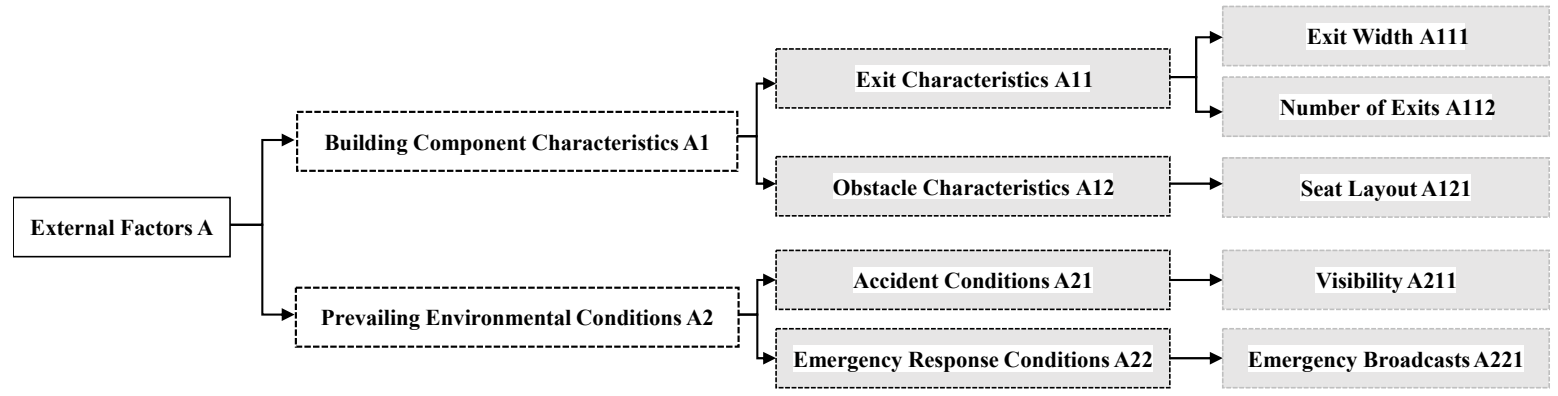

Figure 4. Details of the external factors in the AHP model

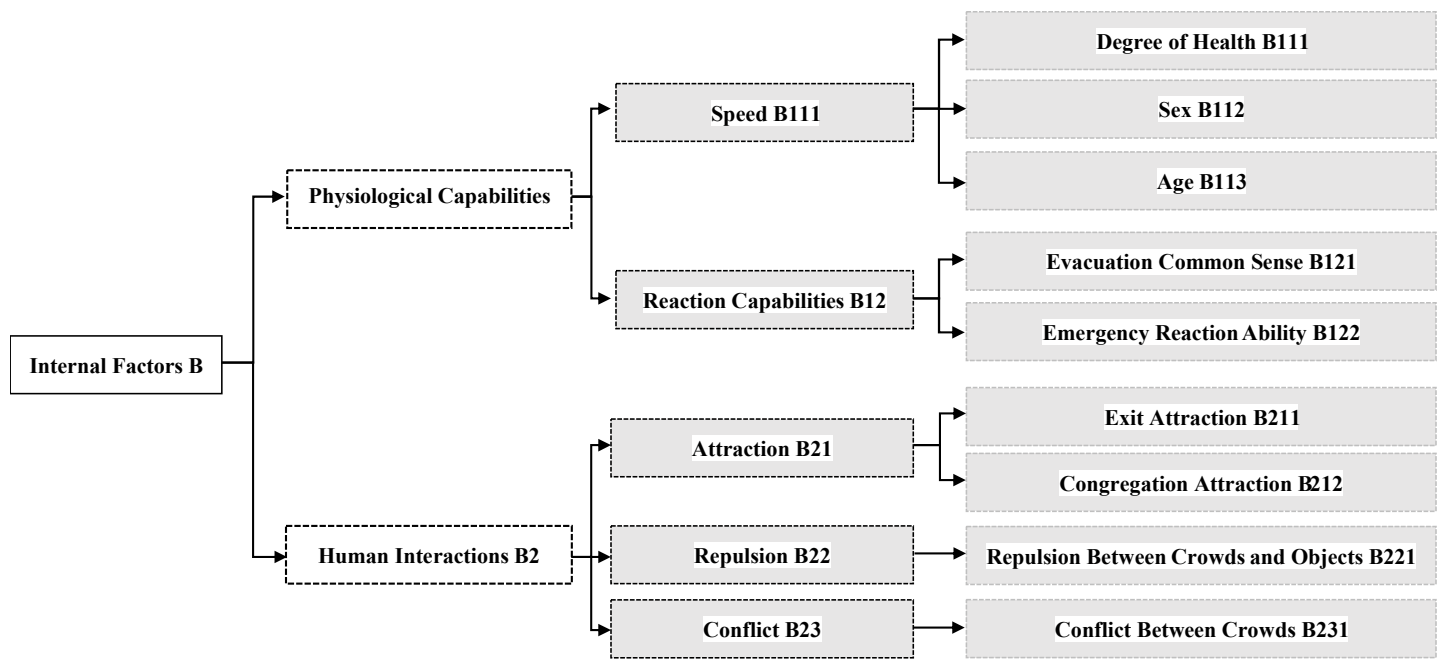

Figure 5. Details of the internal factors in the AHP model

2. Factor weight determination

Initially, $\mathrm{n}$ factors were compared in pairs to obtain their pairwise relative importance, as shown in Table 1.

A judgment matrix was established as,

$$
A=\left(a_{i j}\right)_{n \times n}=\left(\begin{array}{cccc}
a_{11} & a_{12} & \cdots & a_{1 n} \\
a_{21} & a_{22} & \cdots & a_{2 n} \\
\cdots & \cdots & \cdots & \cdots \\
a_{n 1} & a_{n 2} & \cdots & a_{n n}
\end{array}\right)
$$

where $a_{i, j}$ characterizes the relative importance between factors $u_{i}$ and $u_{j}$ and assigned values as shown in Table 2.

The $\mathrm{n}$-th root method (geometric averaging) used in the AHP calculated the factor weights. Initially, the geometric average of each row vector of A was considered (all elements in the same row were multiplied and taken to the (1/n)-th power), and the resulting vector was normalized to obtain 
the weight vector $\underset{\sim}{W}=\left(w_{1}, w_{2}, \ldots \ldots, w_{n}\right)$.

$$
w_{i}=\frac{\left(\prod_{j=1}^{n} a_{i j}\right)^{\frac{1}{n}}}{\sum_{i=1}^{n}\left(\prod_{j=1}^{n} a_{i j}\right)^{\frac{1}{n}}} \quad(i=1,2, \ldots \ldots, n)
$$

In this study, the ranking of the factors entered in the YAAHP software generated the judgment matrix based on expert opinions. Owing to the subjectivity of the experts' assessment, the initial judgment matrix was incomplete and inconsistent. Therefore, to rectify the influences of both subjective and objective factors on the expert judgments, a consistency verification procedure was performed.

Initially, the consistency index CI was calculated, as follows:

$$
C I=\frac{\lambda_{\max }-n}{n-1}
$$

Table 1 Pairwise relative importance of influencing factors

\begin{tabular}{ccccc}
\hline & $u_{1}$ & $u_{2}$ & $\ldots \ldots$ & $u_{n}$ \\
\hline$u_{1}$ & $a_{11}$ & $a_{12}$ & $\ldots \ldots$ & $a_{1 n}$ \\
$u_{2}$ & $a_{21}$ & $a_{22}$ & $\ldots \ldots$ & $a_{2 n}$ \\
$\ldots \ldots$ & $\ldots \ldots$ & $\ldots \ldots$ & $\ldots \ldots$ & $\ldots \ldots$ \\
$u_{n}$ & $a_{n 1}$ & $a_{n 2}$ & $\ldots \ldots$ & $a_{n n}$ \\
\hline
\end{tabular}

Table 2 Meanings of the element values in the judgment matrix

\begin{tabular}{cl}
\hline Value & Interpretation (relative importance between two factors) \\
\hline 1 & The two factors have the same degree of importance. \\
5 & The former factor is slightly more important than the latter. \\
7 & The former factor is notably more important than the latter. \\
9 & The former factor is considerably more important than the latter. \\
$2,4,6,8$ & $\begin{array}{l}\text { The former factor is extremely more important than the latter. } \\
\text { The intermediate values between the adjacent values above represent the corresponding } \\
\text { intermediate levels of relative importance. }\end{array}$ \\
\hline
\end{tabular}

where $\lambda_{\max }$ is the maximum eigenroot of the judgment matrix, given by the formula:

$$
\lambda_{\max }=\sum_{i=1}^{n} \frac{\left(P_{w}\right)_{i}}{n w_{i}}=\sum_{i=1}^{n} \frac{\left(A \underset{\sim}{W^{T}}\right)_{i}}{n w_{i}}=\frac{1}{n} \sum_{i=1}^{n} \frac{\sum_{j=1}^{n} a_{i j} w_{j}}{w_{i}}
$$

Next, we consulted Table 3 to obtain the random indicator RI. Five hundred samples of judgment matrices of orders 2-12 were constructed using a random method, and their consistency indexes were calculated to obtain the average consistency index of a random judgment matrix of each corresponding size. Table 3 lists the average random consistency index values (RI) for positive reciprocal matrices of orders $2-12$.

Table 3 RI values for judgment matrices of various dimensions

\begin{tabular}{cccccccccccc}
$\mathrm{n}$ & 2 & 3 & 4 & 5 & 6 & 7 & 8 & 9 & 10 & 11 & 12 \\
$\mathrm{RI}$ & 0.00 & 0.58 & 0.90 & 1.12 & 1.24 & 1.32 & 1.41 & 1.45 & 1.49 & 1.52 & 1.54 \\
\hline
\end{tabular}

Finally, the consistency ratio CR was calculated as follows: 


$$
C R=\frac{C I}{R I}
$$

When $\mathrm{CR}<0.1$, the judgment matrix satisfied the consistency requirement; when $\mathrm{CR} \geq 0.1$, the judgment matrix presented poor consistency and had to be modified until the requirement of $\mathrm{CR}<0.1$ was satisfied. The factor weights were then arithmetically calculated based on the expert results, and the resulting weight values are listed in Tables 4 and 5.

Table 5 shows that the influence of external factors is generally stronger than that of internal factors. Among them, the building component characteristics and people's physiological capabilities were the core of this evacuation assessment. Additionally, the exit width, seat layout, visibility, speed, and reaction capabilities were crucial to the evacuation process.

Table 4 Comprehensive evaluation of influencing factor weight results

\begin{tabular}{lll}
\hline Number & $\mathrm{A}$ & $\mathrm{B}$ \\
\hline Single Weight & 0.5696 & 0.4304 \\
Total Weight & 0.5696 & 0.4304 \\
\hline
\end{tabular}

Table 5 Weights of individual influencing factors for the railway station waiting hall assessment

\begin{tabular}{|c|c|c|c|c|c|c|c|c|}
\hline Number & A1 & A11 & A111 & A112 & A12 & A121 & & \\
\hline Single Weight & 0.3084 & 0.1352 & 0.0531 & 0.0821 & 0.1732 & 0.1732 & & \\
\hline Total Weight & 0.3084 & 0.0417 & 0.0164 & 0.0253 & 0.0534 & 0.0534 & & \\
\hline Number & $\mathrm{A} 2$ & A21 & A211 & A22 & A212 & A221 & & \\
\hline Single Weight & 0.2612 & 0.1983 & 0.1983 & 0.0585 & 0.0629 & 0.0629 & & \\
\hline Total Weight & 0.2612 & 0.0518 & 0.0518 & 0.0153 & 0.0164 & 0.0164 & & \\
\hline Number & B1 & B11 & B111 & B112 & B113 & B12 & B114 & B115 \\
\hline Single Weight & 0.2982 & 0.1538 & 0.0593 & 0.0352 & 0.0593 & 0.1444 & 0.0588 & 0.0856 \\
\hline Total Weight & 0.2982 & 0.0459 & 0.0091 & 0.0054 & 0.0091 & 0.0431 & 0.0085 & 0.0124 \\
\hline Number & B2 & B21 & B211 & B212 & $\mathrm{B} 22$ & B221 & B23 & B231 \\
\hline Single Weight & 0.1322 & 0.0303 & 0.0216 & 0.0087 & 0.0437 & 0.0437 & 0.0582 & 0.0582 \\
\hline Total Weight & 0.1322 & 0.0040 & 0.0029 & 0.0012 & 0.0058 & 0.0058 & 0.0077 & 0.0077 \\
\hline
\end{tabular}

\subsection{Evacuation simulations}

Based on the AHP method discussed above, the weight of each subfactor is determined. As this approach is based on summarizing subjective evaluations using a statistical method, and it is not possible to quantify the extent of the influence of certain factors, Table 6 presents the impact factors and the hierarchical model list according to the AHP based on expert interviews. The impact of some factors was determined based on the experience of experts, while the impact of other factors (indicated by the black dots in the table) must be determined by simulation.

The accuracy of SIMULEX using in crowd evacuation simulation in large spaces has been proved (Wu, 2016; Wu et al., 2018). In this method of analysis, only one factor is allowed to change at a time, and it is assumed that the other factors remain unchanged. In the considered scenario, we preset 11,000 people in the waiting hall to approach the maximum possible number of passengers considered in the design of the station. The preparation time was $20 \mathrm{~s}$ (random assignment $\pm 10 \mathrm{~s}$ ). Table 7 presents the architectural data, environmental data, and simulation scenarios.

Figure 6 shows the evacuation process (original scenario) for the railway station simulated by SIMULEX. The black squares indicate the exits; there are eight, ten, four, and five exits on the north, south, west, and east side, respectively. Initially, we selected the starting grid cell for evacuation, and the software found the optimal evacuation route by generating a set of broken lines from the starting grid cell, using a path search algorithm. Each broken line was $0.25 \mathrm{~m}$ long, perpendicular to the equidistant line, and pointed in the direction of the exit grid cell. The simulation lasted $5 \mathrm{~min}$ and $15 \mathrm{~s}$. 
Table 6 Data collection for the original scenario

\begin{tabular}{|c|c|c|c|}
\hline Input & Influencing factor & $\begin{array}{l}\text { Data acquisition } \\
\text { mode }\end{array}$ & Reason \\
\hline \multirow{5}{*}{$\begin{array}{l}\text { Building } \\
\text { Parameters }\end{array}$} & Floor plan & $\begin{array}{c}\text { Field observations } \\
\text { Measurement }\end{array}$ & Based on construction drawings and field check \\
\hline & Exits & $\begin{array}{c}\text { Field observations } \\
\text { Measurement }\end{array}$ & Based on construction drawings and field check \\
\hline & Obstacles & $\begin{array}{c}\text { Field observations } \\
\text { Measurement }\end{array}$ & $\begin{array}{c}\text { Based on site measurement, no obstacles in construction } \\
\text { drawings }\end{array}$ \\
\hline & Number & Field observations & $\begin{array}{c}\text { Based on the highest possible number of people as per } \\
\text { the station design }\end{array}$ \\
\hline & Density & Calculations & $\begin{array}{c}\text { By software calculations, based on the highest possible } \\
\text { number of people as per the station design }\end{array}$ \\
\hline
\end{tabular}

Personnel Percentages of Field observations/

parameters

Expert interview
Expert interview

- Speed

- Response-time
Expert interview
According to the recorded video and the expert group discussion

The average speeds of different people were modeled based on the study by Belz and Mertens (1994), then the expert group discussed

Based on the study of Joseph and Pandya (1986) and the expert group discussion

Table 7 Evacuation data for the waiting hall

\begin{tabular}{|c|c|}
\hline Type & Data \\
\hline Area & $15600 \mathrm{~m}^{2}$ \\
\hline Plan dimensions & $230 \mathrm{~m} \times 68 \mathrm{~m}$ \\
\hline Staircases & $\begin{array}{l}12 \text { each on both the north and south sides } \\
\text { Individual evacuation width is } 1.6 \mathrm{~m} \text {, total evacuation width is } 19.2 \mathrm{~m}\end{array}$ \\
\hline Escalators & $\begin{array}{l}8 \text { each on both the north and south sides } \\
\text { Individual evacuation width is } 1 \mathrm{~m} \text {, total evacuation width is } 8 \mathrm{~m}\end{array}$ \\
\hline Seats & $\begin{array}{l}5,700 \text {, parallel to security } \\
\text { Dimensions are } 0.55 \mathrm{~m} \times 0.42 \mathrm{~m} \\
\text { Passageway width is } 2 \mathrm{~m}\end{array}$ \\
\hline Security & $\begin{array}{l}8 \text { on the north side, } 10 \text { on the south side } \\
\text { Evacuation width is } 4.8 \mathrm{~m}\end{array}$ \\
\hline Ticket gates & $\begin{array}{l}18 \text { groups } \\
2 \text { turnstiles, } 1 \text { barrier-free ticket gate, } 1 \text { manual ticket check for each group } \\
\text { Turnstile width is } 600 \mathrm{~mm} \text {, barrier-free ticket gate width is } 900 \mathrm{~mm} \text {, manual ticket } \\
\text { check width is } 600 \mathrm{~mm} \\
\text { Total evacuation width is } 2.7 \mathrm{~m}\end{array}$ \\
\hline External Factor A11 & $\begin{array}{l}\text { a. Scenario features: exit widths- } 0.9,1.2,1.5,1.8,2.1 \text {, and } 2.7 \mathrm{~m} \text {. } \\
\text { b. Scenario features: south side exits damaged/west side exits damaged. }\end{array}$ \\
\hline External Factor A12 & $\begin{array}{l}\text { a. Scenario features: longitudinal (the aisle between the seats is parallel to the ticket } \\
\text { inspectors)/transversal (the aisle between the seats is perpendicular to the ticket } \\
\text { inspectors). } \\
\text { b. Scenario features: numbers of aisles-2, 3, and 4; aisle widths-1.5, } 2.1 \text {, and } 2.7 \mathrm{~m} \text {. }\end{array}$ \\
\hline External Factor A21 & a. Scenario feature: reduced the speed of the evacuees \\
\hline
\end{tabular}




\begin{tabular}{lll}
\hline External Factor A22 & a. & Scenario feature: Premovement time reduced by 2 min. \\
\hline Internal Factors B1 & a. & $\begin{array}{l}\text { Scenario features: Different ratios of passenger type percentages. Passenger types } \\
\text { include male, female, elderly, children, and disabled people. }\end{array}$ \\
\hline Internal Factors B2 & a. & $\begin{array}{l}\text { Scenario features: Different crowd densities in the range of } 0.5 \text { people } / \mathrm{m}^{2}-2 \\
\text { people } / \mathrm{m}^{2}\end{array}$ \\
\hline
\end{tabular}

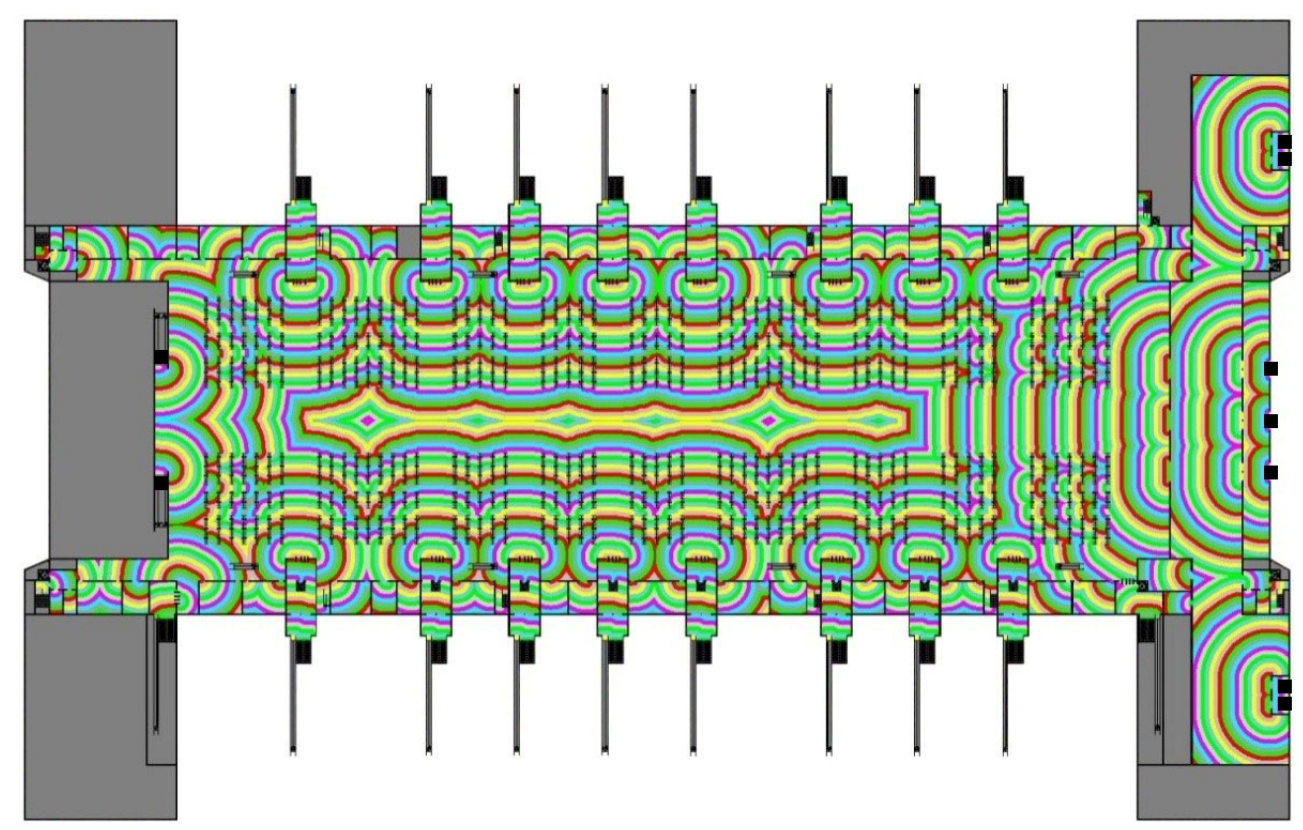

Figure 6. Shortest evacuation paths from each area on the elevated platform of the railway station

\section{Results}

Based on the scenario tested in Section 2.3, we analyzed the influence of each variable (each factor in the AHP model) on the evacuation process under the condition that the other variables remained unchanged.

\subsection{Building component characteristics}

\subsubsection{Exit characteristics: exit width and number of exits}

The exit width is important owing to its special function in several architectural structures and its effect on the evacuation process (Heliövaara et al. 2012; Kurdi et al. 2018). In our research object, the maximum and minimum exit width of a ticket gate was 2.7 and $0.6 \mathrm{~m}$, respectively. To optimize the evacuation efficiency, we determined the relationship between the evacuation time and exit width by varying it. A series of simulation experiments were performed with exit widths of $0.9,1.2,1.5,1.8$, 2.1 , and $2.7 \mathrm{~m}$. Figure 7 depicts the evacuation speeds corresponding to the different exit widths. Although the speed increases logarithmically with the increasing exit width, the effect on evacuation weakens gradually.

In a room with multiple exits, the people's decision of which exit to use is invariably influenced by the time required for egress (Liao et al. 2014; Frank and Dorso 2015; Ronchi et al. 2016). In this study, we investigated the layout effects of multiple exits in the waiting hall of a large railway station in China. The main entrance of the waiting hall includes gates on both the north and south sides. The ticket inspector stations on the west and east sides, normally the check-in points, act as evacuation exits in emergencies. We considered a scenario where either the south or the west side exits of the waiting hall were damaged. Figure 8 compares the evacuation processes in the original scenario and the scenarios with damaged exits. The egress time for the entire crowd was longer with damaged exits, particularly, the damage to the main exits substantially influenced the evacuation efficiency; the total time was twice as that of a normal evacuation. 


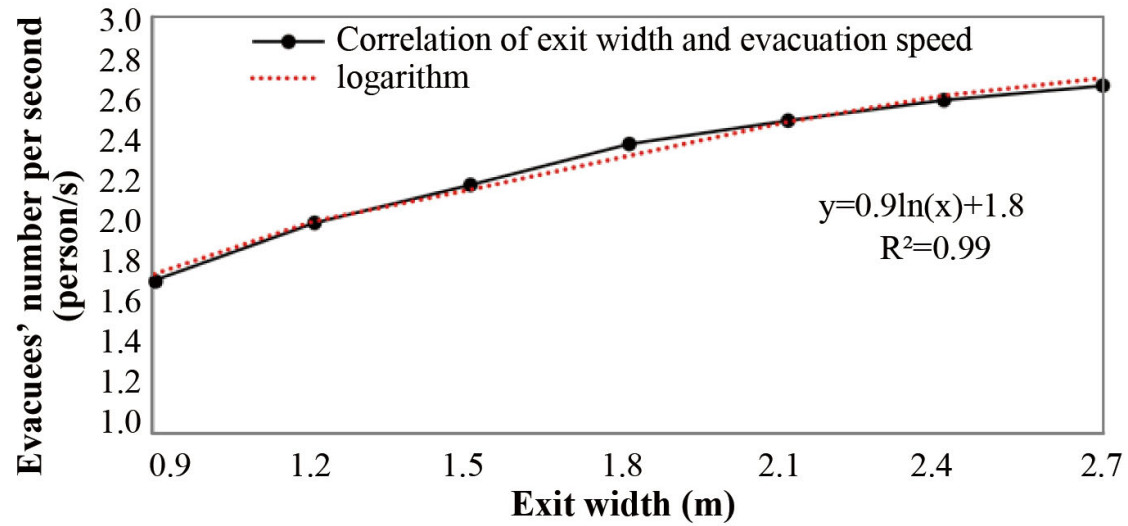

Figure 7. Correlation between the exit width and the evacuation flow

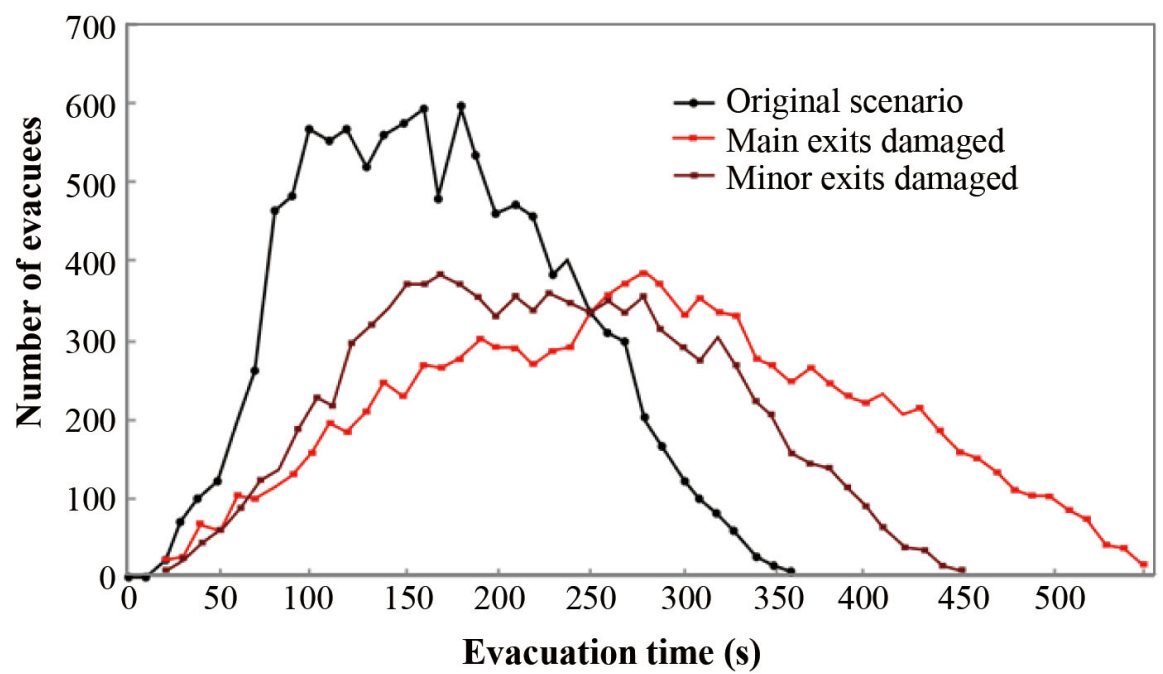

Figure 8. Comparison between the original scenario and scenarios in which either the main exits or secondary exits are damaged

\subsubsection{Obstacle characteristics: seat layout}

The seats in a waiting hall are obstacles that cannot be neglected. We first discuss the influence of the seating arrangement orientation on the evacuation efficiency. The layout of the seats are characterized as either longitudinal (the aisles between the seats are parallel to the ticket inspectors) or transversal (the aisles between the seats are perpendicular to the ticket inspectors), and all the ticket inspectors are parallel to the exits. Figure 9 depicts a comparison of the number of evacuees with the evacuation time under these seating orientations from $70 \mathrm{~s}$ to $170 \mathrm{~s}$ (peak flow period). The periods corresponding to the egress of the first and last $5 \%$ of the evacuees were excluded to avoid the boundary limit conditions (Schadschneider et al. 2009). The flow in the transversal layout was higher than that of the longitudinal layout, and the overall evacuation time with the transversal layout was $85.2 \%$ of the time required with the longitudinal layout.

Due to the spatial constraints in the seating areas of a waiting hall, the aisles are narrow with numerous rows of seats, leading to high congestion. Therefore, we investigated the influence of the spacing between the seats. In this study, the seating area in the waiting hall was approximately $20 \mathrm{~m}$ wide and divided into three columns by two 1.5 -m-wide aisles in the middle, corresponding to ticket gates. Additionally, $2.7 \mathrm{~m}$ wide aisles were set aside in the middle of every five or eight rows for check-in queuing. The width of each queuing channel was determined by the ticket gate position and was unchanged. Scenarios with two, three, and four columns were simulated with an aisle width of $2.1 \mathrm{~m}$, the same as that of the original scenario. In addition, scenarios with different aisle widths between each column $(1.5 \mathrm{~m}, 2.1 \mathrm{~m}$, and $2.7 \mathrm{~m})$ were simulated for the case of three columns, the same number of columns as the original scenario. Figures 10 and 11. compare the number of evacuees 
with the evacuation time under these different aisle arrangements from $70 \mathrm{~s}$ to $170 \mathrm{~s}$ (peak flow period).

The results demonstrated that it is highly beneficial to arrange the seating areas in groups and place the aisles between each group, as a continuous multirow arrangement significantly reduces the evacuation efficiency. The evacuation time does not decrease monotonically with an increasing number of aisles, as it depends on the aisle width. Specifically, the maximum exit flow in the simulated scenarios with different aisle widths ranged from 143 to 122 , to 92 people $/ \mathrm{m}$ for an aisle width of $2.7,2.1$, and $1.5 \mathrm{~m}$, respectively. Most notably, once the flow reached its peak in the narrow aisles $(1.5 \mathrm{~m})$, the evacuation speed decreased due to overcrowding.

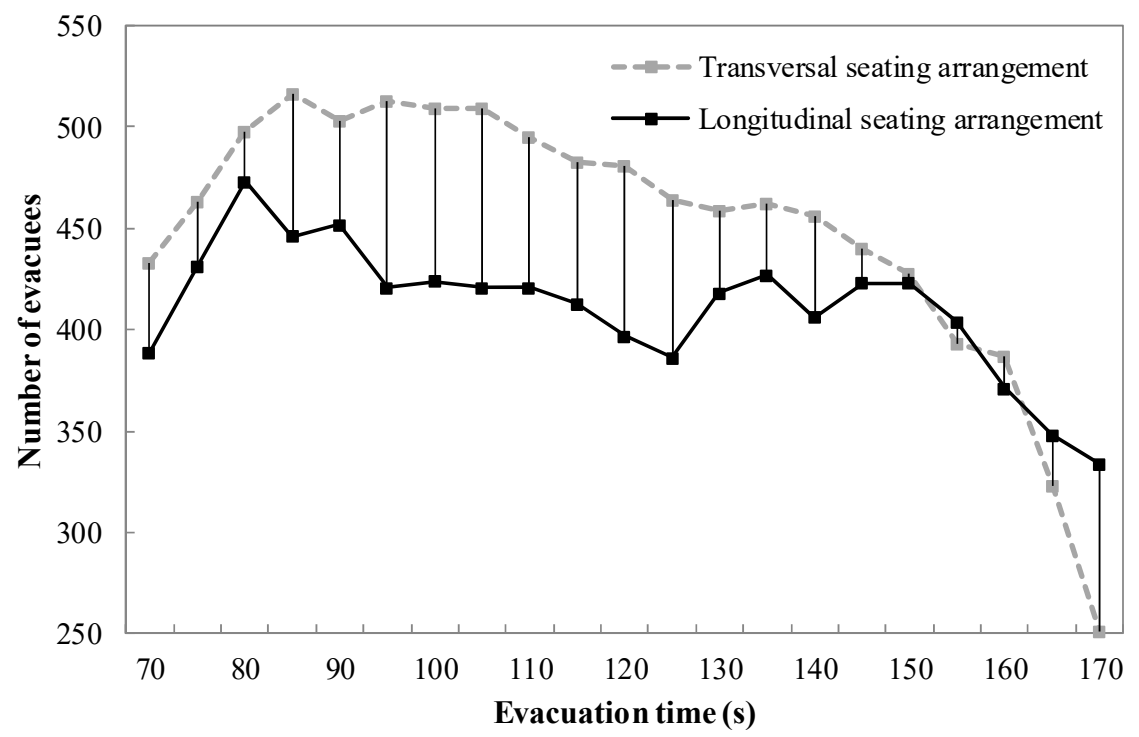

Figure 9. Comparison of the number of evacuees and the evacuation time with different seat layouts

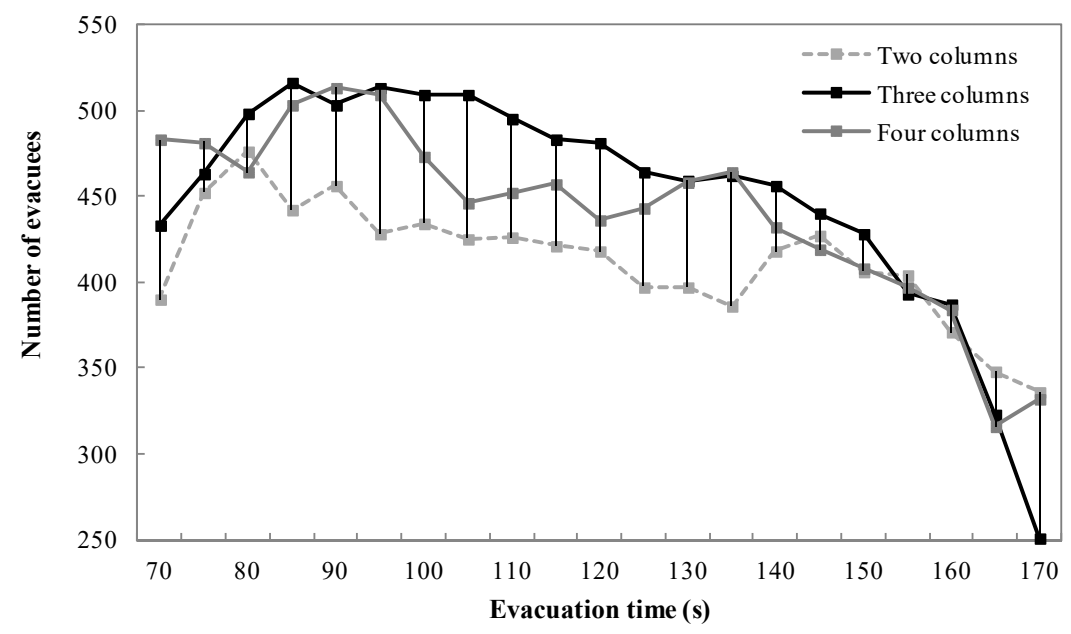

Figure 10. Comparison between the number of evacuees and the evacuation time with different numbers of seating columns 


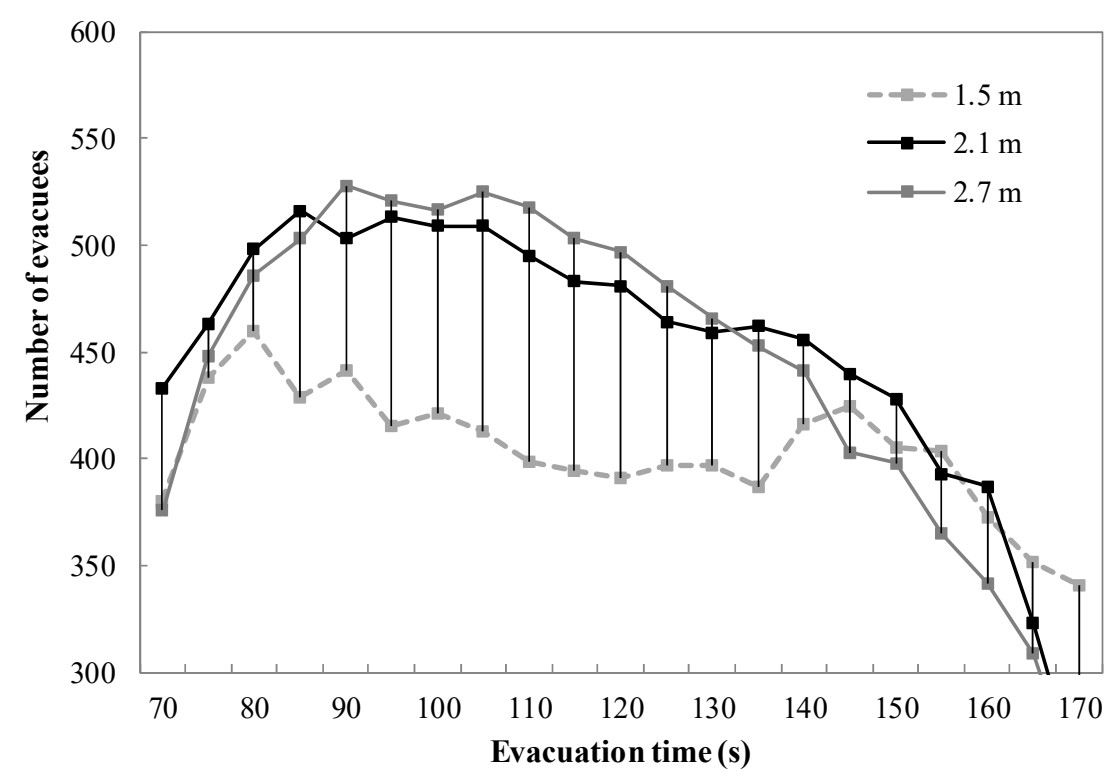

Figure 11. Comparison between the number of evacuees and the evacuation time with different aisle widths

\subsection{Prevailing environmental conditions}

\subsubsection{Accident conditions: visibility}

We reduced the speed of the evacuees to simulate different visibility scenarios. The input data concerning the walking speed were chosen based on the experimental data from previous studies, as summarized in Table 8.

With smoke, the simulation lasted $7 \mathrm{~min}$ and $20 \mathrm{~s}$, which was $39.7 \%$ longer than the original scenario; in a scenario with smoke and no lighting, the simulation lasted 10 min and $25 \mathrm{~s}$, nearly twice as long. The simulation in this study is based on a physical model, assuming that the people will always choose the shortest evacuation route in an emergency. Hence, the limitations of this study require further research, because the evacuation process could be more complex if the visibility changes.

Table 8 Summary of measured walking speeds from various experiments

\begin{tabular}{ccc} 
Passenger category & With smoke & With smoke, no lighting \\
\hline Male & $1.26 \mathrm{~m} / \mathrm{s}$ & $0.98 \mathrm{~m} / \mathrm{s}$ \\
Female & $1.02 \mathrm{~m} / \mathrm{s}$ & $0.89 \mathrm{~m} / \mathrm{s}$ \\
Elderly & $0.73 \mathrm{~m} / \mathrm{s}$ & $0.52 \mathrm{~m} / \mathrm{s}$ \\
Children & $0.69 \mathrm{~m} / \mathrm{s}$ & $0.55 \mathrm{~m} / \mathrm{s}$ \\
& $0.58 \mathrm{~m} / \mathrm{s}$ without help & $0.46 \mathrm{~m} / \mathrm{s}$ without help \\
Disabled people & $0.72 \mathrm{~m} / \mathrm{s}$ with help & $0.57 \mathrm{~m} / \mathrm{s}$ with help \\
& $0.82 \mathrm{~m} / \mathrm{s}$ with electric wheelchair & $0.58 \mathrm{~m} / \mathrm{s} \mathrm{with} \mathrm{electric} \mathrm{wheelchair}$ \\
& $0.63 \mathrm{~m} / \mathrm{s}$ with manual wheelchair & $0.44 \mathrm{~m} / \mathrm{s}$ with manual wheelchair \\
\hline
\end{tabular}

\subsubsection{Emergency broadcasts}

In this section, we compare an evacuation simulation with the informative fire warning (IFW) to an evacuation simulation without the IFW. The IFW can reduce the overall evacuation time by up to 2 min compared to a fire alarm bell in a large and complex building (Canter et al. 1988). Therefore, we considered a setting to change the premovement time. Notably, the total evacuation time reduced by $35 \mathrm{~s}$ with the IFW, and the evacuation efficiency improved by 13.2\%. In Figure 12, the solid line and dashed line indicate the evacuation time based on the number of evacuees with and without the IFW, respectively. During the first $40 \mathrm{~s}$ of the evacuation process, the IFW speeds up the time where the evacuees receive a signal indicating a hazard, thereby reducing the premovement duration and 
hastening the evacuation. In the first half of the evacuation process, the total evacuation rate in the simulation with IFW is higher than that of the simulation without IFW.

To compare the influences of different alarm signals on the evacuation direction and speed, we assumed that the IFW message was played only through the loudspeaker above the east exits. In a large railway station, the background noise can reach 70-75 $\mathrm{dB}$ (Wu et al. 2018), and the evacuees cannot hear the IFW message clearly if the received sound pressure level (SPL) of the broadcast is $\leqslant$ $82 \mathrm{~dB}$, after the addition of the signal-to-noise ratio. Therefore, we reduced the premovement time by 2 min only at those evacuee positions where an SPL above $82 \mathrm{~dB}$ was obtained for the emergency broadcast (Wang et al. 2018). The simulation results revealed that the number of evacuees escaping through the east-west exits is close to the average with no IFW. However, 545 more people evacuated through the exits equipped with IFW than through those without IFW, and significantly more people evacuated through the east exits than the west. The discrepancy in the number of evacuees between the east and west exits was considerably evident (reaching 9 people/s) during the evacuation with IFW. Thus, Figure 13 demonstrates that the evacuation efficiency with IFW is superior.

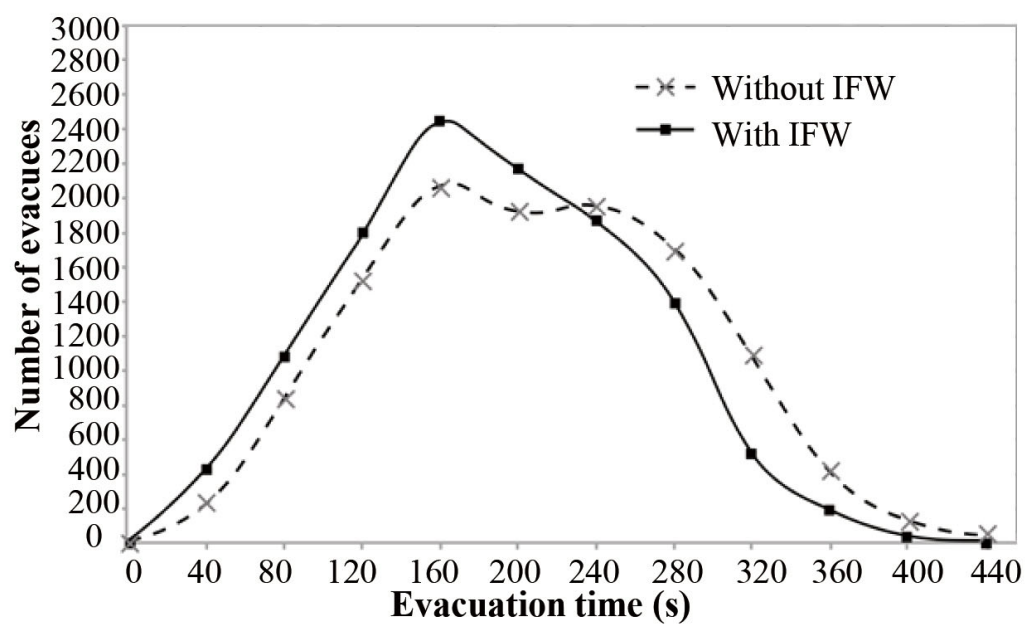

Figure 12. Influence of emergency broadcasts on the total number of evacuees

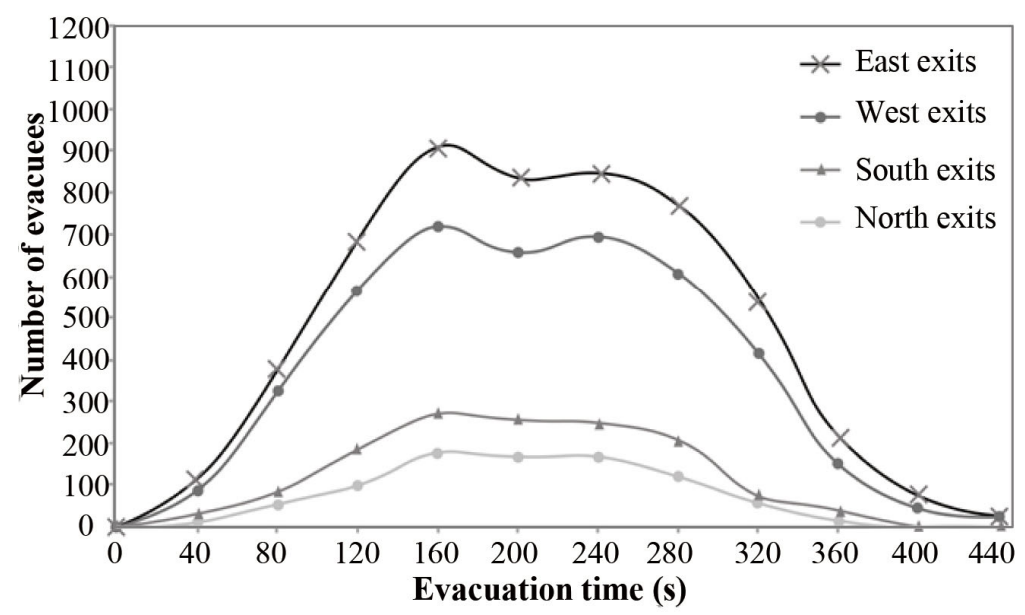

(a) Number of evacuees without IFW 


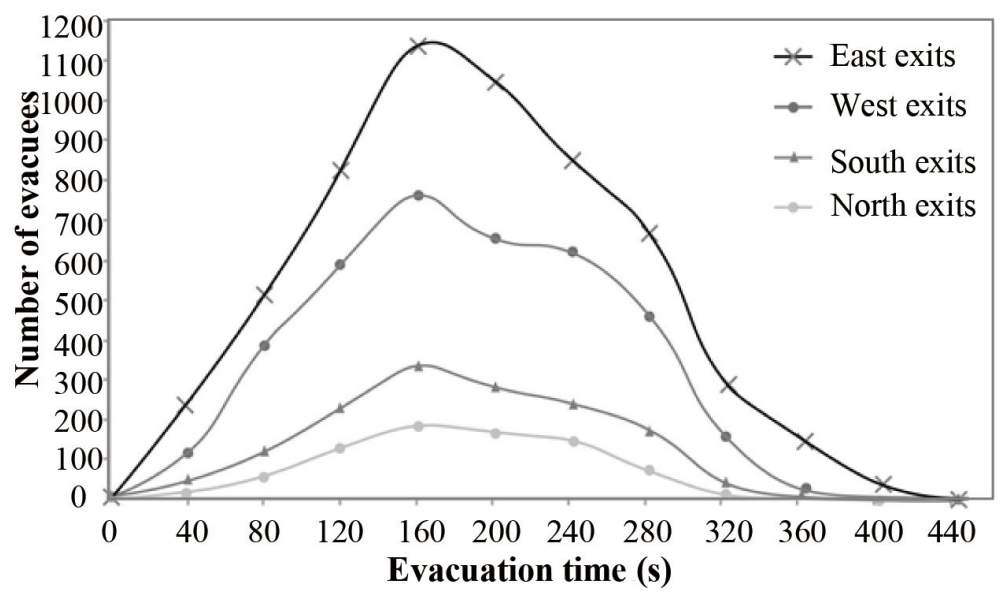

(b) Number of evacuees with IFW

Figure 13. Influence of an emergency broadcast at only the east exits on the evacuation time and the number of evacuees at each set of exits

\subsection{Physiological capabilities and human interactions}

In this section, evacuation simulations with different ratios of passenger type percentages are compared with the original scenario. Under the assumption that the total number of evacuees remained unchanged, the percentage of evacuees of one type was adjusted proportionally. Figure 14 compares the total evacuation time concerning the different categories of evacuees. The evacuation time decreased with the increase in the percentage of male evacuees; once the proportion reached $40 \%$, the decreasing trend diminished gradually. An increased percentage of either male or female evacuees with the same crowd density reduced the evacuation time, although the percentage of male evacuees exerted a stronger influence than that of the female evacuees. In contrast, higher proportions of people with obvious restrictions, i.e., elderly people, children, and people with disabilities resulted in a significant increase in evacuation time. People with disabilities exerted the strongest influence, followed by elderly people.

In this section, we examine a bottleneck situation as a function of different crowd densities. In these simulations, the density varied from 0.5 to 2.0 people $/ \mathrm{m} 2$. Figure 15 shows that the total evacuation time significantly correlated with the occupant density. With increasing density, the total evacuation time increased exponentially.

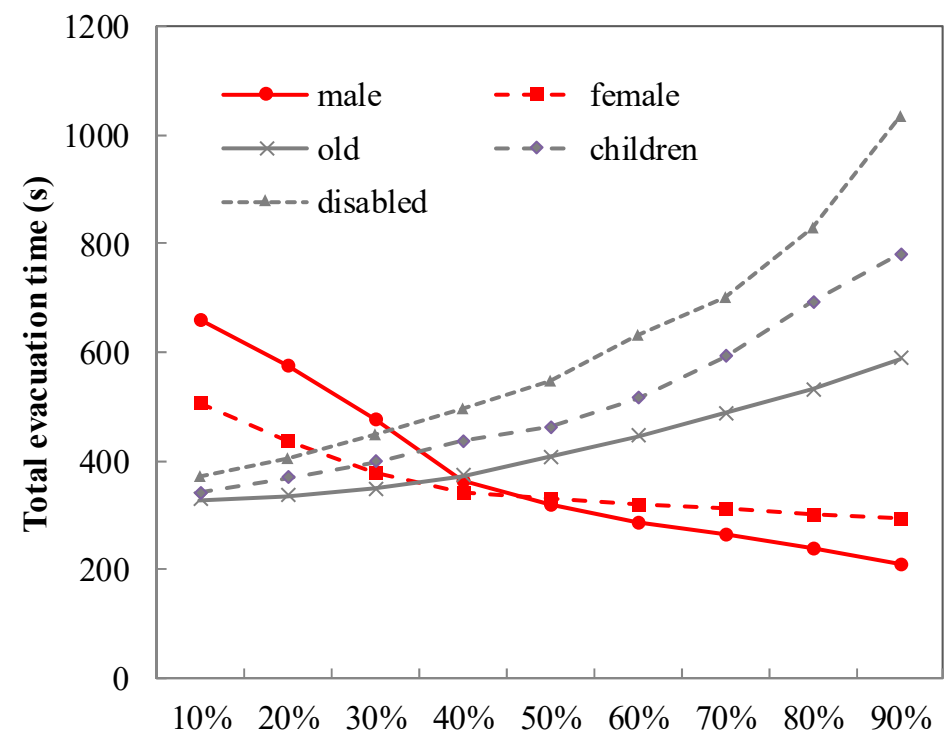

Passenger type percentage

Figure 14. Comparison of total evacuation time with different passenger type percentages 


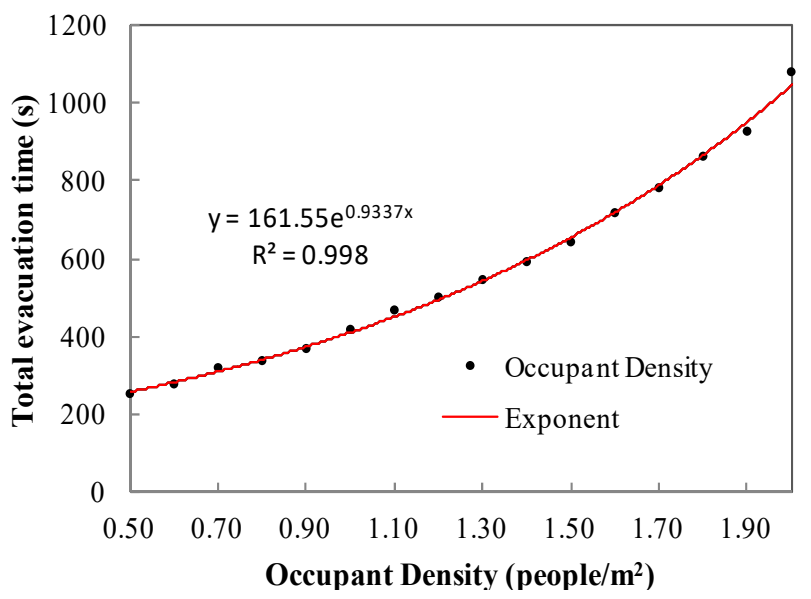

Figure 15. Comparison of total evacuation time with different occupant densities

The composition of the crowd also affects the evacuation process. For example, the speed will be faster with more male evacuees; but with more children present, adults will need to assist them, slowing the evacuation speed. Similarly, the overall speed will be reduced if there are more elderly people. Therefore, our study compared the combined effects of different crowd densities on the evacuation time considering different crowd compositions, as shown in Figure 16. The results revealed that the crowd density significantly affected the evacuation time regardless of the passenger type percentage, as the evacuation time increased with the crowd density.

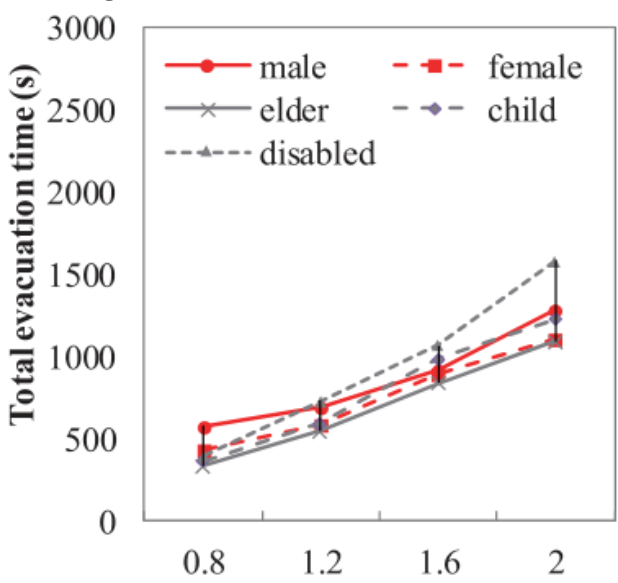

Crowd density (people/m²)

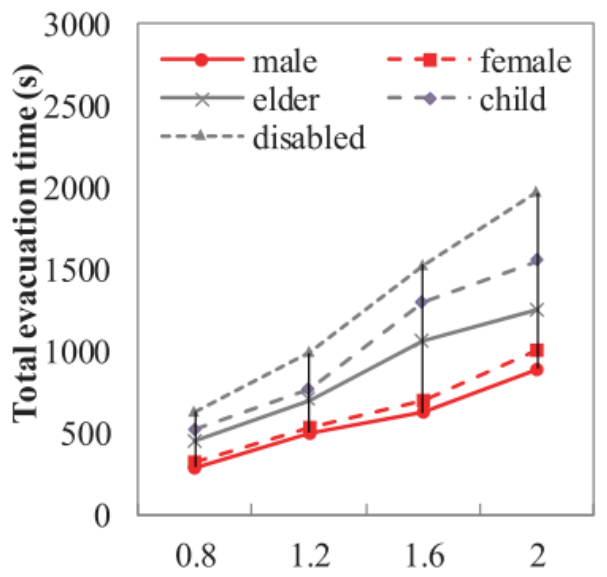

Crowd density (people/ $\left.\mathrm{m}^{2}\right)$

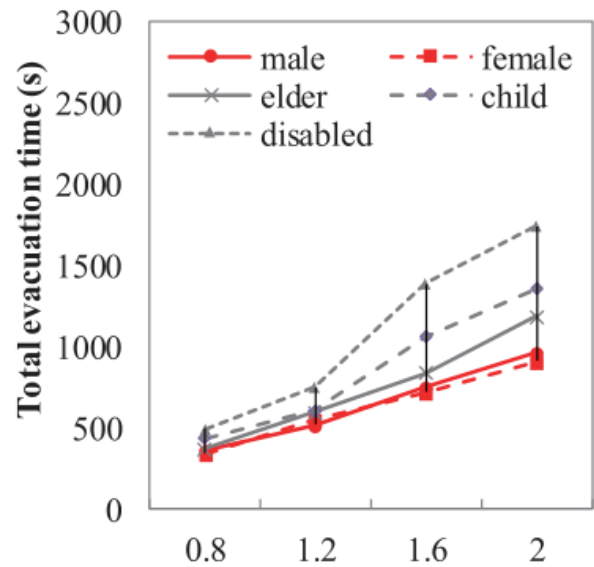

Crowd density (people/m²) (a)

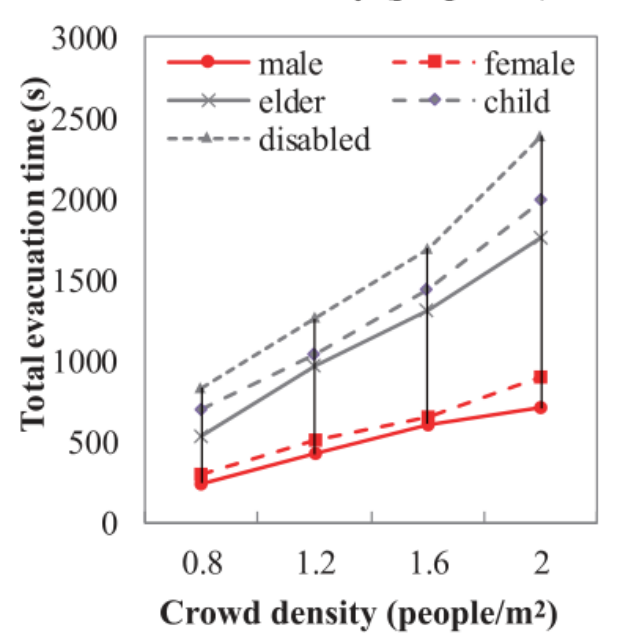

Crowd density (people/m²)

(b)

(c)

(d)

Figure 16. Comparison of the influences of different passenger type percentages and crowd densities on the evacuation time: (a) crowd composition with $20 \%$ of the indicated passenger type; (b) 
crowd composition with $40 \%$ of the indicated passenger type; (c) crowd composition with $60 \%$ of the indicated passenger type; (d) Crowd composition with $80 \%$ of the indicated passenger type

\section{Discussion}

The previous studies analyzed how various external and internal factors affected the evacuation process (Ronchi et al. 2012) in a waiting hall in a large railway station. Our study validated that the evacuation efficiency was influenced by the building itself, the environment, and the people in it. This paper also reports the first multifactor simulation in a large railway station, extending the previous findings of social influence, by analyzing how the evacuees' characteristics affect the decision to evacuate, and thereby the evacuation process.

Overall, the evacuees' behaviors are strongly influenced by the damage to the main exits than the secondary exits. While several studies found that symmetrical configurations led to higher efficiency than asymmetrical configurations (Huang and Guo 2008), we reached the opposite conclusion in the case of exit damage: the evacuation time was more when the exits were uniformly distributed (main exits damaged) than when they were non-uniformly distributed (secondary exits damaged). We also studied the influence of seats acting as obstacles and found that it was beneficial for the seats to face the ticket inspectors. Surprisingly, the comparison revealed that the design specifications and the simulation results disagreed considerably; these results are contrary to those of other studies (Zhu and Yang 2010; Galea et al. 2006). When the aisle width is narrow, the conflict between evacuees from both sides reduces the efficiency of evacuation (Dong et al. 2015). However, contrary to Zhu and Yang's (2010) study, the evacuation efficiency was more affected by the width of a single aisle than the number of aisles. Regarding the prevailing environmental conditions in fire scenarios, the evacuee walking speed was significantly influenced by the lighting and smoke (Fridolf et al. 2013). The lighting and IFW reduced the overall evacuation time in a large and complex building. The results extended the previous findings (Ramachandran 1991) by demonstrating that the IFW influenced the movement time during the first half of the evacuation process along with the premovement time. A strong negative correlation exists between the percentage of male/female evacuees and the total evacuation time, with the male evacuees exerting a stronger influence than the female evacuees. In contrast, the relationship between the percentage of elderly/child/disabled evacuees and the total evacuation time is positive. People with disabilities had the greatest influence, followed by elderly people. Furthermore, an increase in the crowd density had a negative effect regardless of the passenger type percentage. These results support the simulation results of Ma et al. (2017) while suggesting that the percentages of different passenger types and the crowd density collectively affect the evacuation efficiency.

Finally, our results demonstrated that observations and surveys regarding the behavior of crowds in large spaces can be investigated under controlled simulation conditions in a laboratory. This approach is advantageous as researchers can systematically manipulate specific variables of interest to test their causal influence on the evacuation process in well-defined scenarios. In future, researches on new subjective evaluations with different personnel and building attributes can use the method described in this study for safety assessments of large spaces by modifying the objective evaluation scenario. Additionally, this simulation method will facilitate the experimental investigation of other features such as the interactions between the social and physical environments, the weights of the corresponding factors, and other environmental variables, such as the signage, architectural layout, and exit locations.

\section{Conclusion}

Evaluating the safe evacuation of large-spaced crowded buildings is challenging. Although the influencing factors and their weights can be obtained through subjective evaluation, the degree and status of influence of each factor are difficult to determine. Therefore, this paper proposes a risk evaluation methodology for evaluating the risk factors and their weights using the Analytic Hierarchy Process, following which the degree and status of influence of each factor can be determined through evacuation simulations. In this study, the risk factors were selected by a panel of experts and ranked in terms of their relative importance. Based on these rankings, the factor weights were generated using the YAAHP software. A univariate analysis was applied to determine the influence of each 
factor on the evacuation process in various simulation scenarios. The proposed risk evaluation methodology provided a useful, practical, effective, and optimized approach to evaluate the risk for scenarios involving crowds or large-volume buildings. This method offers a new way of prioritizing the elements in safety design.

The proposed risk evaluation method has the following advantages over the traditional method:

- The risk factors and their relative importance weights are evaluated in terms of precise numerical values rather than in a linguistic manner, making the evaluation more objective and accurate.

- The risk factors are organized in a hierarchical model, making the proposed method more comprehensive, realistic, and practical.

- The proposed approach avoids highly subjective, costly, and time-consuming investigation processes based on questionnaires and interviews.

- Additional risk factors can be incorporated in the hierarchical model and simulated in the evacuation simulation software if necessary.

\section{References}

Abolghasemzadeh P (2013). A comprehensive method for environ- mentally sensitive and behavioral microscopic egress analysis in case of fire in buildings. Safety Science, 59: 1-9.

Ashe B, Shields TJ (1999). Analysis and modeling of the unannounced evacuation of a large retail store. Fire and Materials, 23: 333-336.

Belz R, Mertens P (1994). SIMULEX - A multiattribute DSS to solve rescheduling problems. Annals of Operations Research, 52: 107-129.

Bode NWF, Codling EA (2013). Human exit route choice in virtual crowd evacuations. Animal Behaviour, 86: 347-358.

Bryan JL (1957). A study of the survivors reports on the panic in the fire at the Arundel Park Hall in Brooklyn, University of Maryland, USA.

Bryan JL (2002). SFPE Handbook of Fire Protection Engineering. 3rd edn. Quincy, MA, USA: National Fire Protection Association.

Canter D, Powell J, Booker K (1988). Psychological aspects of informative fire warning systems (No. BR127). Garston, UK: Building Research Establishment.

Carey M, McCartney M (2004). An exit-flow model used in dynamic traffic assignment. Computers \& Operations Research, 31: 1583-1602.

Carlson JM, Alderson DL, Stromberg SP, et al. (2014). Measuring and modeling behavioral decision dynamics in collective evacuation. PLoS One, 9: e87380.

Chang L, He X, Song W (2016). Research on steel structure building evacuation based on empirical formula method and Simulex. Acta Scientiarum Naturalium Universitatis Nankaiensis, 49(6): 21-28. (in Chinese)

Chen B, Chin J (2000). The analysis of performance-based smoke management and egress system in new-type MRT station. Mechanical Engineering.

Chow WK, Ng CMY (2008). Waiting time in emergency evacuation of crowded public transport terminals. Safety Science, 46: 844-857.

Dalkey NC (1969). The Delphi Method: An Experimental Study of Group. Santa Monica, CA, USA: RAND Corporation.

Dietenberger MA, Boardman CR (2017). EcoSmart fire as structure ignition model in wildland urban interface: predictions and validations. Fire Technology, 53: 577-607.

Dong LY, Chen L, Duan XY (2015). Modeling and simulation of pedestrian evacuation from a single-exit classroom based on experimental features. Acta Physica Sinica, 64: 220505. (in Chinese)

Frank GA, Dorso CO (2015). Evacuation under limited visibility. International Journal of Modern Physics C, 26: 1550005 . 
Fridolf K, Nilsson D, Frantzich H (2013). Fire evacuation in underground transportation systems: A review of accidents and empirical research. Fire Technology, 49: 451-475.

Fridolf K, Nilsson D, Frantzich H (2016). Evacuation of a metro train in an underground rail transportation system: flow rate capacity of train exits, tunnel walking speeds and exit choice. Fire Technology, 52: 1481-1518.

Galea ER, Galparsoro JMP (1994). A computer-based simulation model for the prediction of evacuation from mass-transport vehicles. Fire Safety Journal, 22: 341-366.

Galea ER, Finney KM, Dixon AJP, et al. (2006). An analysis of exit availability, exit usage and passenger exit selection behaviour exhibited during actual aviation accidents. The Aeronautical Journal, 110: 239-248.

Gray-Graves A, Turner KW, Swan JH (2011). The level of willingness to evacuate among older adults. Gerontology \& Geriatrics Education, 32: 107-121.

Guo R, Huang H, Wong SC (2012). Route choice in pedestrian evacuation under conditions of good and zero visibility: Experimental and simulation results. Transportation Research Part B: Methodological, 46: 669-686.

Heliövaara S, Kuusinen JM, Rinne T, et al. (2012). Pedestrian behavior and exit selection in evacuation of a corridor-An experimental study. Safety Science, 50: 221-227.

Huang H, Guo R (2008). Static floor field and exit choice for pedestrian evacuation in rooms with internal obstacles and multiple exits. Physical Review E, 78: 021131.

Joseph M, Pandya PK (1986). Finding response times in a real-time system. The Computer Journal, 29: 390-395.

Kennedy WD, Li SK, Harvey NA (2001). Simulation of escape from rail tunnels using Simulex. In: Proceedings of Rail Transit Conference, Miami, FL, USA.

Ketchell N, Manford GJ, Kandola B (1995). Evacuation modeling: A new approach. IN: Proceedings of Asiaflam'95, Hong Kong, China.

Kisko TM, Francis RL (1985). EVACNET+: A computer program to determine optimal building evacuation plans. Fire Safety Journal, 9: 211-220.

Kuligowski E, Peacock R, Wiess E, et al. (2013). Stair evacuation of older adults and people with mobility impairments. Fire Safety Journal, 62: 230-237.

Kurdi HA, Al-Megren S, Althunyan R, et al. (2018). Effect of exit placement on evacuation plans. European Journal of Operational Research, 269: 749-759.

Li S-J, Lee S-H (2008). A study on the development of emergency evacuation simulator considering the characteristic of the behavior pattern in crowding. Journal of the Korea Academia-Industrial cooperation Society, 9: 1319-1327. (in Korean)

Liao W, Zheng X, Cheng L, et al. (2014). Layout effects of multi-exit ticket-inspectors on pedestrian evacuation. Safety Science, 70: 1-8.

Lo SM, Fang Z, Lin P, et al. (2004). An evacuation model: the SGEM package. Fire Safety Journal, 39: 169-190. Lovreglio R, Ronchi E, Kinsey MJ (2020). An online survey of pedestrian evacuation model usage and users. Fire Technology, 56: 1133-1153.

Ma Y, Li L, Zhang H, Chen T (2017). Experimental study on small group behavior and crowd dynamics in a tall office building evacuation. Physica A: Statistical Mechanics and its Applications, 473: 488-500.

McConnell NC, Boyce KE, Shields J, et al. (2010). The UK 9/11 evacuation study: Analysis of survivors' recognition and response phase in WTC1. Fire Safety Journal, 45: 21-34.

Meng F, Zhang W (2014). Way-finding during a fire emergency: an experimental study in a virtual environment. Ergonomics, 57: 816-827.

Mott MacDonald Simulation Group (2012). Simulation of Transient Evacuation and Pedestrian movementS-STEPS User Manual 4.1 Version.

Nam H, Kwak S, Jun C (2016). A study on comparison of improved floor field model and other evacuation models. Journal of the Korea Society for Simulation, 25(3): 41-51. (in Korean) 
Olsson PÅ, Regan MA (2001). A comparison between actual and predicted evacuation times. Safety Science, 38 : $139-145$.

Ozel F (2001). Time pressure and stress as a factor during emergency egress. Safety Science, 38: 95-107.

Phipps DL, Meakin GH, Beatty PCW (2011). Extending hierarchical task analysis to identify cognitive demands and information design requirements. Applied Ergonomics, 42: 741-748.

Pires TT (2005). An approach for modeling human cognitive behavior in evacuation models. Fire Safety Journal, 40 : $177-189$.

Ramachandran G (1991). Informative fire warning systems. Fire Technology, 27: 66-81.

Rød SK, Botan C, Holen A (2012). Risk communication and worried publics in an imminent rockslide and tsunami situation. Journal of Risk Research, 15: 645-654.

Ronchi E, Colonna P, Capote J, et al. (2012). The evaluation of different evacuation models for assessing road tunnel safety analysis. Tunnelling and Underground Space Technology, 30: 74-84. Ronchi E, Nilsson D, Kojić S, et al. (2016). A virtual reality experiment on flashing lights at emergency exit portals for road tunnel evacuation. Fire Technology, 52: 623-647. Saloma C, Perez GJ, Tapang G, et al. (2003). Self-organized queuing and scale-free behavior in real escape panic. Proceedings of the National Academy of Sciences of the United States of America, 100: 11947-11952. applications. In: Meyers R (ed), Encyclopedia of Complexity and Systems Science. New York: Springer. with self-designated mobility impairments. Fire Safety Journal, 44: 881-893.

Shiwakoti N, Sarvi M, Rose G, et al. (2011). Animal dynamics based approach for modeling pedestrian crowd egress under panic conditions. Transportation Research Part B: Methodological, 45: 1433-1449. Shiwakoti N, Gong Y, Shi X, et al. (2015). Examining influence of merging architectural features on pedestrian crowd movement. Safety Science, 75: 15-22. Sime J (2001). An occupant response shelter escape time (ORSET) model. Safety Science, 38: 109-125. Steinfeld E (2006). Evacuation of people with disabilities. Journal of Security Education, 1: 107-118. Thompson PA, Marchant EW (1995a). Testing and application of the computer model 'SIMULEX'. Fire Safety Journal, 24: 149-166. Thompson PA, Marchant EW (1995b). A computer model for the evacuation of large building populations. Fire Safety Journal, 24: 131-148.

648 Thompson PA, Wu J, Marchant E (1996). Modelling evacuation in multi-storey buildings with Simulex. Fire 649 Engineers Journal, 56(185): 6-11.

650 Thunderhead Engineering (2012). Pathfinder 2012.1.0802 Version. Technical Reference.

651 Vilar E, Rebelo F, Noriega P, et al. (2014). Effects of competing environmental variables and signage on route-choices in simulated everyday and emergency wayfinding situations. Ergonomics, 57: 511-524. Wang J, Lo S, Wang Q, et al. (2013). Risk of large-scale evacuation based on the effectiveness of rescue strategies under different crowd densities. Risk Analysis, 33: 1553-1563.

655 Wang C, Ma H, Wu Y, et al. (2018). Characteristics and prediction of sound level in extra-large spaces. Applied 656 Acoustics, 134: 1-7.

657 Wind Y, Saaty TL (1980). Marketing applications of the analytic hierarchy process. Management Science, 26: $658 \quad 641-658$.

659 Wood PG (1972). Fire Research Note 953. Borehamwood: Building Research Establishment.

$660 \mathrm{Wu}$ Y (2016). Emergency evacuation safety research for large railway stations based on auditory perception. PhD 661 Thesis, Harbin Institute of Technology, China. (in Chinese) 
Wu Y, Kang J, Wang C (2018). A crowd route choice evacuation model in large indoor building spaces. Frontiers of Architectural Research, 7: 135-150.

$\mathrm{Xu}$ Y, Liao S, Liu M (2019). Simulation and assessment of fire evacuation modes for long underwater vehicle tunnels. Fire Technology, 55: 729-754.

Zhao CM, Lo SM, Zhang SP, et al. (2009). A post-fire survey on the pre-evacuation human behavior. Fire Technology, 45: 71-95.

Zheng X-P, Zhong T-K, Zhang J-W (2008). Exploration into the evacuation of crowds in public buildings. China Safety Science Journal, 18(1): 27-33. (in Chinese)

Zhou J-H (1990). On the architectural creation of China's major comprehensive railway passenger station. Architectural Journal, 1990(4): 10-18. (in Chinese)

Zhu K-J, Yang L-Z (2010). The effects of exit position and internal layout of classroom on evacuation efficiency. Acta Physica Sinica, 59(11): 7701-7707. (in Chinese) 